\title{
Capitulo 1
}

\section{A UTILIZAÇÃO DE FEIJÃO CARIOCA BIOFORTIFICADO COMO OPÇÃO PARA AUMENTO DO CONTEÚDO DE FERRO E ZINCO EM BARRAS DE CEREAIS}

\author{
DOI: $10.37423 / 200501022$
}

Tayna Geaquinto Rebello (Universidade Federal do Espírito Santo (UFES), Departamento de Educação Integrada em Saúde, Vitória, Espírito Santo).tayna.rebello@yahoo.com.br

Camila Soares de Magalhães (Universidade Federal do Espírito Santo (UFES), Centro de Ciências da Saúde, Programa de Pós-Graduação em Nutrição e Saúde (PPGNS), Vitória, Espírito Santo).mylamag@yahoo.com.br

José Luiz Viana de Carvalho (Embrapa Agroindústria de Alimentos - CTAA). jose.viana@embrapa.br

Erika Madeira Moreira da Siva (Universidade Federal do Espírito Santo (UFES), Centro de Ciências da Saúde, Programa de Pós-Graduação em Nutrição e Saúde (PPGNS), Nitória, Espírito Santo).erika.m.silva@ufes.br

Daniela Alves Silva (Universidade Federal do Espírito Santo (UFES). Departamento de Educação Integrada em Saúde, Vitória, Espírito Santo).contato.daniela.nut@gmail.com

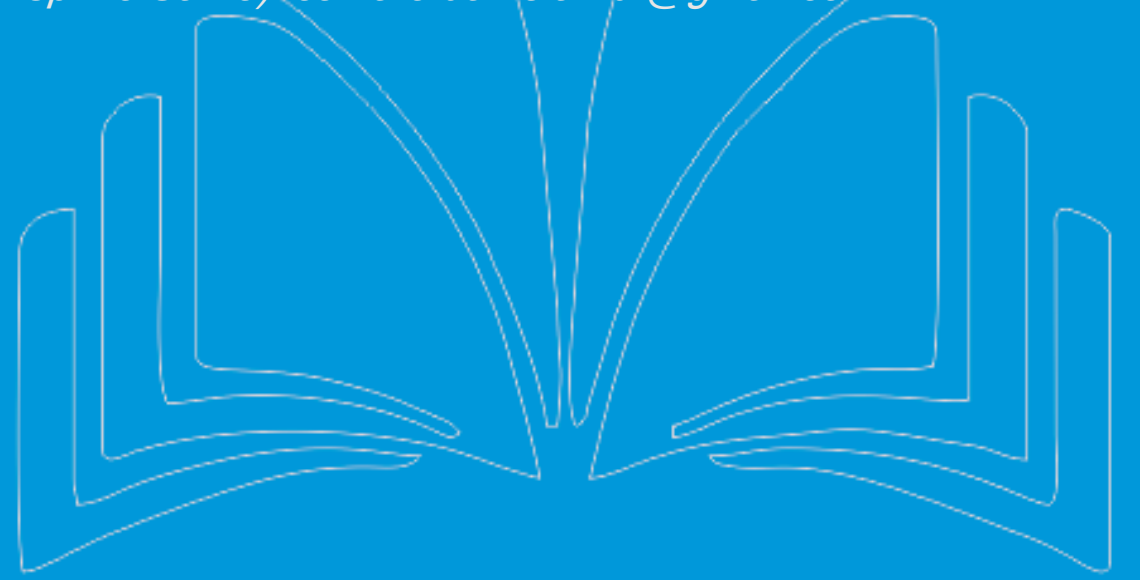


RESUMO: As barras de cereais estão facilmente disponíveis em estabelecimentos comerciais, apresentam embalagens compactas e possuem preço relativamente baixo, que varia de acordo com sua composição. Além dos ingredientes tradicionais que compõem as formulações de barras de cereais, outros ingredientes alternativos podem ser introduzidos nessas formulações para aumentar seu valor nutritivo. A combinação arroz e feijão constitui a base da dieta da população brasileira, sendo altamente nutritiva e interessante para a indústria. O feijão, além de ser um alimento de fácil acesso à população, de baixo custo e estar inserido na cultura alimentar brasileira, é um dos alimentos que faz parte das pesquisas de biofortificação coordenadas pela EMBRAPA. Este trabalho teve como objetivo elaborar barras de cereais à base de arroz e feijão (convencional e biofortificado), além de avaliar as características de preparo, medições, composição nutricional e custos. Para o preparo das barras foram utilizados feijões do tipo carioca, de origem comercial e biofortificados (BRS Cometa). As barras de cereais apresentaram peso médio da porção de $60 \pm 2,78 \mathrm{~g}$, custo unitário de $R \$ 1,10$ e valor energético de 122 kcal em meia porção. Foi possível elaborar barras de cereais com inclusão de arroz e feijão (convencional e biofortificado) que apresentassem custos e características físicas semelhantes. Entretanto, a barra formulada com feijão biofortificado apresentou maior teor de ferro e zinco do que a com feijão convencional. A inserção de arroz e feijão na composição das barras de cereais fez com que as mesmas apresentassem boa propriedade funcional, por serem fontes de fibras. Dessa forma, a utilização de feijões, em especial biofortificados, em barras de cereais se torna uma alternativa alimentar capaz de agregar valor nutricional superior ao produto.

Palavras chave: Novos produtos, leguminosas, BRS Cometa, biofortificação. 


\section{INTRODUÇÂO}

No início da década de 90, as barras de cereais foram inseridas no mercado como alternativa saudável de produto de confeitaria, ao mesmo tempo em que havia maior interesse, por parte dos consumidores, em cuidados com a saúde e com a alimentação (MELO et al., 2010). No entanto, mesmo com essa proposta de alimento saudável, análises de composição do produto demonstraram que algumas variações possuíam características semelhantes às observadas em confeitos comuns como, por exemplo, as quantidades de gordura e açúcares, diferindo-se apenas pelo conteúdo de fibra alimentar (SANTOS, 2010).

Devido ao crescente interesse pelas barras de cereais, a indústria alimentícia tem investido na diversificação de sabores e atributos das mesmas. De acordo com Marchese e Novello (2017), antigamente os principais consumidores de barras de cereais eram os esportistas, entretanto, nos dias de hoje esse produto é consumido por toda população.

As barras de cereais são elaboradas a partir de uma mistura de cereais, fontes de vitaminas, minerais, fibras, proteínas e carboidratos, basicamente (PEUCKERT et al., 2010). Características como textura, sabor e propriedades físicas são definidas pela combinação adequada e complementariedade dos ingredientes que fazem parte das formulações. Além disso, estão facilmente disponíveis em estabelecimentos comerciais, apresentam embalagens compactas, o que facilita o transporte e o consumo, além de apresentarem preço relativamente baixo, que varia de acordo com sua composição (FERREIRA et al., 2018).

Entretanto, atualmente no mercado, são disponíveis diversas barras de cereais cuja lista de ingredientes inclui aditivos como aromatizantes, corantes, conservantes, emulsificantes, umectantes, bem como o uso de açúcares como a sacarose e o xarope de glicose e a adição de gorduras vegetais (REBELLO; MAGALHÃES; SILVA, 2019) o que decai sobre o valor nutricional do produto tornando-o inferior.

Os ingredientes tradicionais das formulações de barras de cereais são aveia, milho, soja, trigo, arroz e outros cereais, frutas, nozes e chocolate (CZAIKOSKI et al., 2016). Porém, no contexto de produtos saudáveis existem vários ingredientes que podem ser introduzidos nessas formulações para aumentar seu valor nutritivo, trazendo assim mais benefícios à saúde (SILVA et al., 2011). Um exemplo interessante é a utilização de arroz e feijão. 
A combinação arroz e feijão constitui a base da dieta da população brasileira, sendo altamente nutritiva, uma vez que a proteína do arroz é deficiente no aminoácido lisina, mas compensada pela lisina presente no feijão. Este, por sua vez, é deficiente do aminoácido metionina, que é compensado pela metionina do arroz, ou seja, um complementa o outro tornando tal combinação completa em aminoácidos essenciais (JORGE et al., 2014).

Por ser um alimento de fácil acesso à população, de baixo custo e estar inserido na cultura alimentar brasileira, o feijão é um dos alimentos que faz parte das pesquisas de biofortificação coordenadas pela Empresa Brasileira de Pesquisa Agropecuária (EMBRAPA).

A biofortificação consiste em um processo de cruzamento de plantas da mesma espécie, gerando cultivares mais nutritivos. O processo também é conhecido como melhoramento genético convencional e não pode ser confundido com transgenia (BIOFORT, 2020).

Sendo assim, analisando a crescente abertura do mercado e do consumidor para alimentos saudáveis e práticos, este trabalho teve como objetivo elaborar barras de cereais à base de arroz e feijão (convencional e biofortificado), além de avaliar as características de preparo, medições, composição nutricional e custos.

\section{MATERIAL E MÉTODOS}

\subsection{INGREDIENTES}

Para o preparo das barras à base de arroz e feijão convencional e biofortificado foram utilizados: flocos de arroz, flocos de aveia, mel Camará ${ }^{\circledR}$, açúcar refinado União ${ }^{\circledR}$, essência de baunilha $\operatorname{Dr}$. Oetker ${ }^{\circledR}$ e feijão carioca Juju ${ }^{\circledR}$, todos obtidos no comércio local do município de Vitória - ES. O feijão carioca BRS Cometa foi gentilmente cedido pela Embrapa Arroz e Feijão (Santo Antônio de Goiás - GO).

\subsection{Preparo da massa, do recheio e das barras}

Foram realizados dois testes em dias distintos, denominados T1 (pré-teste) e T2, visando padronização do receituário e ajuste do experimento. Em ambos, os flocos de arroz foram submetidos a uma temperatura de $180^{\circ} \mathrm{C}$ no forno durante 10 minutos para a retirada de umidade do mesmo. Após esse tempo foi retirado do forno e misturado a aveia em flocos. Para o preparo da massa foram adicionados em uma panela açúcar, mel e água, levando-se ao fogo médio até que fosse alcançado o ponto de "calda de açúcar" (caramelização). Ao chegar a este ponto, os flocos de arroz juntamente com a aveia, foram incorporados à calda até que todos estivessem cobertos pelo caramelo. No T1, desligou-se o 
fogo e a mistura foi despejada numa superfície de mármore devidamente higienizada com álcool 70 \% e untada com óleo de soja. Já no T2, a mistura foi despejada em uma forma de alumínio também untada com óleo de soja para facilitar o corte das porções. Depois laminou-se a massa com o auxílio de uma faca grande.

Para o recheio, os grãos de feijão foram selecionados, descartando-se sujidades e, em seguida, foram pesados $300 \mathrm{~g}$ em balança digital da marca/modelo Even-CT-6200AS-BI, com capacidade máxima de $6200 \mathrm{~g}$ e precisão de 0,01g. O feijão foi colocado em um recipiente com $450 \mathrm{~mL}$ de água, permanecendo de remolho, sob refrigeração, durante aproximadamente 22 horas. Posteriormente, o feijão foi lavado em água corrente e cozido em panela de pressão. Esse processo foi realizado com os dois tipos de feijão (convencional e biofortificado).

Seguindo como referência as técnicas utilizadas por Sousa (2011) para o preparo de recheio de feijão doce, após cozidos, os grãos junto com o caldo, foram liquidificados até atingirem uma textura de creme. Após liquidificado, o creme foi transferido para uma panela e adicionado açúcar e essência de baunilha, os quais foram levados ao fogo médio e misturados até alcançar uma consistência semelhante a doce em pasta. Após, adicionou-se uma colher de sopa do recheio, contendo $20 \mathrm{~g}$, em uma das lâminas de massa, nivelando com auxílio de uma espátula.

\subsection{Informações Nutricionais das barras de cereais}

A composição nutricional das barras foi descrita de acordo com as RDCs no 350 e no 360 da Agência Nacional de Vigilância Sanitária (ANVISA) (BRASIL, 2003) e os valores calculados foram obtidos por meio da Tabela brasileira de composição dos alimentos (TACO, 2011). Para essência de baunilha utilizou-se a tabela United States Department of Agriculture (USDA), e para o feijão BRS Cometa, as informações disponibilizadas por Pereira et al. (2015).

O valor diário de referência foi descrito de acordo com as DRIs (Dietary Reference Intakes), propostas pelo Institute of Medicine (IOM, 2001, 2002, 2005, 2011). Além disso, o custo das preparações foi calculado de acordo com o rendimento das barras laminadas e do recheio, considerando o preço atual de mercado de cada ingrediente.

\subsection{MEDIÇÕES DAS BARRAS}

Foram analisados comprimento, largura e espessura das lâminas das barras e das barras de cereais recheadas produzidas. As mesmas medidas foram feitas para três barras de cereais comercializadas 
no mercado a fim de comparar o produto desenvolvido com os disponíveis para o consumidor. Para tal, utilizou-se uma régua plástica de $30 \mathrm{~cm}$.

\subsection{TRATAMENTO DOS DADOS}

Os dados foram armazenados no Microsoft Excel ${ }^{\circledR}$, procedendo-se análises descritivas das medições e valor nutricional das barras de cereais formuladas.

\section{RESULTADOS E DISCUSSÃO}

\subsection{ELABORAÇÃO DAS BARRAS DE CEREAIS RECHEADAS}

Para formulação das barras, no T1 (pré-teste), foram seguidas as técnicas descritas por Sousa (2011), com algumas adaptações como: tempo de forno que os flocos de arroz foram submetidos (10 min), dimensões das lâminas de barra ( $1 \mathrm{~cm}$ de espessura) e quantidade de recheio colocado em cada barra (20 g). Porém, mesmo com as adaptações, houve sobra de $67 \mathrm{~g}$ de massa da barra, cerca de $254 \mathrm{~g}$ de recheio do feijão convencional e $232 \mathrm{~g}$ de recheio do feijão biofortificado. Tais sobras podem ser justificadas devido as alterações realizadas nas dimensões das lâminas de barra. Visando reduzir essas sobras foi realizado o T2 com mais alterações e ajustes, e esta foi a formulação final utilizada. No T2 também houve sobras, porém elas foram minimizadas, sendo $14,5 \mathrm{~g}$ de massa de barra, $88,7 \mathrm{~g}$ de recheio de feijão convencional e 91,15g de recheio de feijão biofortificado.

Em relação ao recheio, ambos os tipos de feijão foram submetidos aos mesmos processos de prépreparo e preparo. Porém, houve diferença no tempo de cozimento, sendo que o feijão biofortificado demandou 20 minutos a mais que o feijão convencional para finalizar o seu cozimento, totalizando 50 minutos. Esse tempo foi diferente do descrito por Peloso et al. (2006) que afirmar que o cultivar BRS Cometa possui um tempo de cozimento de 33 minutos. Tal fato, de acordo com Morais et al. (2010) pode ser influenciado por diversos fatores, dentre eles o tempo de armazenamento, o ambiente de armazenamento, as condições de embalagem e a capacidade de penetração de água nos grãos.

Quanto ao custo das barras de cereais, evidenciou-se que o valor de cada porção com peso médio de $60 \pm 2,78$ g, foi de $R \$ 1,10$. Em geral, as barras de cereais que são encontradas no comércio possuem preços que variam de $\mathrm{R} \$ 0,90$ a $\mathrm{R} \$$ 3,40 e tem variação de peso entre $20 \mathrm{~g}$ a $30 \mathrm{~g}$.

Entretanto, cabe ressaltar que, à este valor não foi incorporado gastos com energia, água, mão de obra, entre outros. Apenas o custo bruto com os ingredientes foi utilizado para o cálculo. 
O custo das barras desenvolvidas foi o mesmo independentemente do tipo de feijão utilizado, uma vez que considerou-se o valor de venda do feijão convencional para ambas pelo fato do feijão biofortificado ter sido gentilmente cedido pela EMBRAPA. De fato, a EMBRAPA, disponibiliza o grão biofortificado para os produtores rurais por meio de estratégias de transferência de tecnologia que vão desde o momento da disponibilização à verificação de adoção da mesma, e também para parcerias de pesquisas que ela estabelece, para que se dê, efetivamente, o uso e a adoção da biofortificação (BORGES et al., 2013).

\subsection{CARACTERÍSTICAS NUTRICIONAIS DAS BARRAS}

Os valores energéticos e de macronutrientes foram semelhantes entre as formulações, com diferenças apenas na quantidade de ferro e zinco (Tabela 1).

Tabela 1 - Informação nutricional das barras de cereais formuladas com arroz e feijão carioca (convencional e biofortificado).

\section{Barra de cereal de arroz e feijão carioca Barra de cereal de arroz e feijão carioca convencional biofortificado}

Porção de $30 \mathrm{~g}$ ( $1 \frac{1}{2}$ unidade) Informação Nutricional
Porção de $30 \mathrm{~g}(1 / 2$ unidade)

Informação Nutricional

\begin{tabular}{cccccc}
\hline \multicolumn{2}{c}{ Quantidade por porção } & $\%$ VD $\left(^{*}\right)$ & \multicolumn{2}{c}{ Quantidade por porção } & $\%$ VD $\left(^{*}\right)$ \\
\hline Valor & $122 \mathrm{kcal}$ ou & $6 \%$ & Valor & $122 \mathrm{kcal}$ ou & $6 \%$ \\
energético & $510 \mathrm{KJ}$ & & energético & $510 \mathrm{KJ}$ & \\
\hline Carboidratos & $28,5 \mathrm{~g}$ & $9 \%$ & Carboidratos & $28,5 \mathrm{~g}$ & $9 \%$ \\
\hline Proteínas & $1,6 \mathrm{~g}$ & $2 \%$ & Proteínas & $1,6 \mathrm{~g}$ & $2 \%$ \\
\hline Gorduras & $0,3 \mathrm{~g}$ & $0 \%$ & Gorduras & $0,3 \mathrm{~g}$ & $0 \%$ \\
\hline Fibra & $1,5 \mathrm{~g}$ & $6 \%$ & Fibra & $1,5 \mathrm{~g}$ & $6 \%$ \\
\hline Ferro $(\mathbf{m g})$ & $0,3 \mathrm{mg}$ & $2 \%$ & Ferro $(\mathbf{m g})$ & $1,0 \mathrm{mg}$ & $7 \%$ \\
\hline Cálcio $(\mathbf{m g})$ & $5,5 \mathrm{mg}$ & $0 \%$ & Cálcio $(\mathbf{m g})$ & $5,5 \mathrm{mg}$ & $0 \%$ \\
\hline Sódio $(\mathbf{m g})$ & $2,8 \mathrm{mg}$ & $0 \%$ & Sódio $(\mathbf{m g})$ & $2,8 \mathrm{mg}$ & $0 \%$ \\
\hline Zinco $(\mathbf{m g})$ & $0,1 \mathrm{mg}$ & $1 \%$ & Zinco $(\mathbf{m g})$ & $0,4 \mathrm{mg}^{\star *}$ & $6 \%$ \\
\hline
\end{tabular}

* \% Valores Diários de Referência com base sem uma dieta de 2.000 kcal ou $8.400 \mathrm{KJ}$. Seus valores diários podem ser maiores ou menores dependendo de suas necessidades energéticas. ${ }^{* *}$ Pereira et al. (2015). 
De acordo com Pereira et al. (2015) o feijoeiro-comum destaca-se por ser um dos principais alimentos consumidos pelos brasileiros e por conta do seu aspecto nutricional, que apresenta altos teores de proteínas, fibras, vitaminas, ferro e zinco. A deficiência desses minerais é reconhecida em nível mundial, principalmente em famílias carentes que não tem acesso à proteína animal como carne e produtos lácteos. Então, elevar os níveis de nutrientes, como ferro e zinco, em alimentos que compõem a alimentação das pessoas torna-se uma alternativa válida para atenuar e até mesmo prevenir a desnutrição no Brasil e no mundo. O programa de melhoramento de feijoeiro-comum da Embrapa almeja identificar e desenvolver cultivares de grão preto ou carioca convencional com maiores teores de ferro e zinco.

De forma semelhante ao presente estudo, Landim et al. (2013) desenvolveram biscoitos à base de feijão biofortificado e identificaram ótimo conteúdo de nutrientes nos biscoitos, principalmente em relação ao ferro e zinco. Estes autores caracterizaram os produtos como sendo de grande potencial nutritivo e funcional.

No que diz respeito a porção de barras de cereais, a Legislação Brasileira leva em consideração apenas o percentual de gordura. A RDC no 359/2003 prevê porções de 30 g para as barras de cereais com até $10 \%$ de gordura e essa porção passa a ser de $20 \mathrm{~g}$ e ter até $100 \mathrm{kcal}$, quando o teor de gordura é superior a $10 \%$ (BRASIL, 2003). Por meio do cálculo do valor energético das barras desenvolvidas nesse estudo foi verificado que, os produtos obtidos com ambos os recheios, possuem $122 \mathrm{kcal}$ por porção de $30 \mathrm{~g}$, correspondente a meia unidade. Em geral, a média de calorias contidas nas barras de cereais comercializadas é de $70 \mathrm{kcal}$ a $150 \mathrm{kcal}$, porém o peso da porção da maioria dessas barras equivale a metade da porção das barras desenvolvidas nesse estudo.

No estudo de Melo et al. (2010) foi desenvolvida uma barra de cereal salgada que apresentou $137 \mathrm{kcal}$ em uma porção de $30 \mathrm{~g}$ e, de forma semelhante ao nosso produto, apresentou menor teor de gordura do que as produzidas pelas indústrias de alimentos.

Considerando uma dieta de $2000 \mathrm{kcal}$, o consumo de meia unidade da barra desenvolvida no presente estudo supre em média $6 \%$ do valor energético diário recomendado, levando em consideração as DRIs (IOM, 2001, 2002, 2005, 2011), então, pode-se sugerir o consumo de uma barra inteira em pequenas refeições, como os lanches.

As barras à base de arroz e feijão, elaboradas nesse estudo, apresentam 1,5 g de fibras em uma porção de $30 \mathrm{~g}$, sendo caracterizadas como fonte de fibras, uma vez que de acordo com a Agência Nacional de Vigilância Sanitária (BRASIL, 2012) um alimento pode ser considerado fonte de fibra alimentar caso 
ofereça, no mínimo, $3 \mathrm{~g}$ de fibra em $100 \mathrm{~g}$ do produto ou, no mínimo, 2,5 g por porção. Pode-se dizer que feijão e aveia foram os ingredientes que contribuíram para a quantidade de fibra observada nos produtos formulados. Dias et al. (2010) ao desenvolverem barra de cereais fonte de fibras também utilizaram aveia em sua composição. Gutkoski et al. (2007) afirmam que o uso de aveia na formulação de barras de cereais possibilita obtenção de um produto com alto teor de fibra alimentar.

\subsection{MEDIÇÕES DAS BARRAS}

As barras de arroz e feijão convencional e biofortificado foram padronizadas quanto as suas medidas (Figura 1)

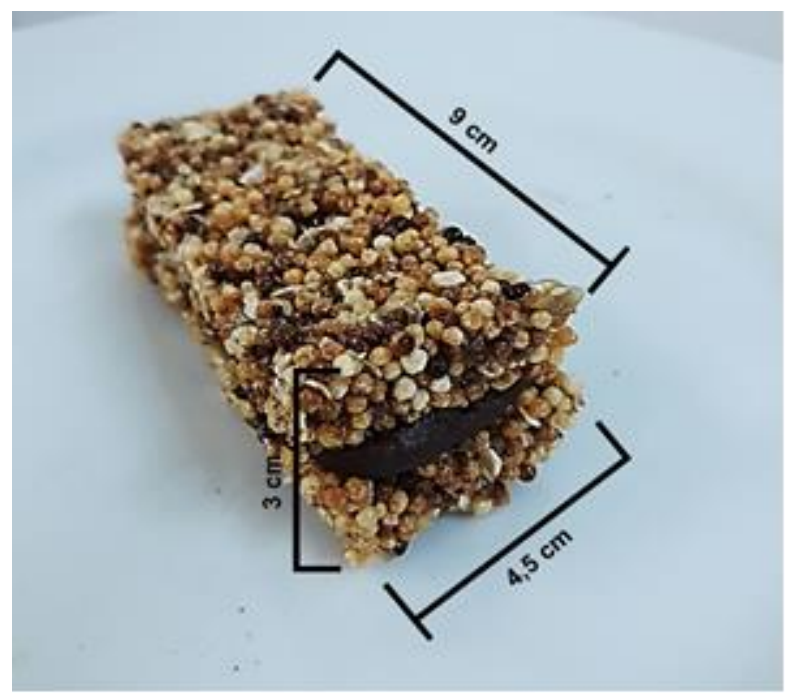

Figura 1 - Medidas de comprimento, largura e espessura das barras formuladas.

Da mesma forma, foram analisadas três barras de cereais de marcas diferentes disponíveis atualmente no mercado (Tabela 2).

Tabela 2 - Caracterização física de barras de cereais disponíveis no mercado.

\begin{tabular}{cccc} 
Medidas & Barra de Cereal 1 & Barra de Cereal 2 & Barra de Cereal 3 \\
\hline Comprimento & $10 \mathrm{~cm}$ & $9,5 \mathrm{~cm}$ & $9 \mathrm{~cm}$ \\
\hline Largura & $4,5 \mathrm{~cm}$ & $3,5 \mathrm{~cm}$ & $3,5 \mathrm{~cm}$ \\
\hline Espessura & $2,5 \mathrm{~cm}$ & $2,5 \mathrm{~cm}$ & $2,5 \mathrm{~cm}$
\end{tabular}

É possível observar que a barra desenvolvida apresenta características físicas bem próximas das barras disponíveis atualmente no mercado. Já a barra de cereal salgada produzida por Marchese e Novello 
(2017) apresentou dimensões de $13 \mathrm{~cm}$ de comprimento, $4 \mathrm{~cm}$ de largura e 1,5 cm de espessura. As barras de cereais com adição de farinha de ameixa desenvolvida por Czaikoski et al. (2016) apresentaram dimensões de $10 \mathrm{~cm}$ de comprimento, $3 \mathrm{~cm}$ de largura e $1 \mathrm{~cm}$ de espessura. No entanto, não há registros na literatura que padronizem tais medidas.

De acordo com Queiroz et al. (2008), o formato retangular das barras de cereais foi determinado visando ser uma alternativa de substituição às barras de chocolate. Além disso, as embalagens individuais, possuem características como praticidade e fácil consumo as mesmas (OLIVEIRA, 2015).

\section{CONCLUSÕES}

Foi possível elaborar barras de cereais à base de arroz e aveia, com inclusão de feijão carioca (convencional e biofortificado) que apresentassem custos e características físicas semelhantes. Porém, vale destacar que a barra com feijão biofortificado apresentou maior teor de ferro e zinco do que a com feijão convencional.

A inserção de arroz e feijão juntamente com aveia na formulação das barras de cereais fez com que as mesmas apresentassem boa propriedade funcional, por serem fontes de fibras.

Desta forma, a utilização de feijões em barras de cereais se torna uma alternativa alimentar de fácil preparo e custo acessível, agregando valor nutricional superior ao produto.

\section{AGRADECIMENTOS}

Ao pesquisador José Luiz Viana de Carvalho da EMBRAPA Agroindústria de Alimentos do Rio de Janeiro, a EMBRAPA Arroz e Feijão de Santo Antônio do Goiás e ao Programa BioFORT.

\section{REFERÊNCIAS}

BIOFORT. Perguntas frequentes. O que é biofortificação? Disponível

em <https://biofort.com.br/perguntas-frequentes/>. Acesso em 26 de maio de 2020.

BORGES, S. M. S.; FIGUEIROA, J. G.; MERLO, T. F. F.; Adoção de variedade de feijão biofortificado por produtores rurais em Girau do Ponciano, Alagoas. Revista GEINTEC, Vol. 3/n. 5/ p.409-417, São Cristóvão/SE - 2013.

BRASIL. Resolução RDC no 359, de 23 de dezembro de 2003. Aprova o Regulamento Técnico de porções de alimentos embalados para fins de rotulagem nutricional. Diário Oficial da União, Poder Executivo, de 26 de dezembro de 2003. 
BRASIL. Resolução RCD no 263, de 22 de setembro de 2005. Aprova o Regulamento Técnico para Produtos de Cereais, Amidos, Farinhas e Farelos. Diário Oficial da União, Poder Executivo, de 23 de setembro de 2005.

BRASIL. Resolução RCD no 54, de 12 de novembro de 2012. Aprova Regulamento Técnico sobre Informação Nutricional Complementar. Diário Oficial da União, Poder Executivo, de 19 de novembro de 2012.

CZAIKOSKI, A. et al.; Avaliação físico-química e sensorial de barras de cereais com adição de farinha de ameixa (Prunus salicina). Revista do Setor de Ciências Agrárias e Ambientais, V.12 N.2 Maio/Ago., 2016.

DEGASPÁRI, C. H.; BLINDER, E. W.; MOTTIN, F. Perfil nutricional do consumidor de barras de cereais. Visão Acadêmica, Curitiba, v.9, n.1, Jan./Jun., 2008.

DIAS, J. M.; YAMAMOTO, L. I.; MANCUSO, A. M. C.; SILVA, M. E. M. P.; Barra de cereais desenvolvida por uma cooperativa popular no contexto da economia solidária. Segurança Alimentar e Nutricional, Campinas, 17(1): 94-103, 2010.

FERREIRA, P. M.; ROBERTO, B. S.; CAMISA J. Caracterização e Aceitabilidade de Barras de Cereais Enriquecidas com Colágeno Hidrolisado. Revista Virtual Química,10 (1), 155-171, março de 2018.

Fundação Instituto Brasileiro de Geografia e Estatística (IBGE). Pesquisa de orçamentos familiares, 2008-2009: despesas, rendimentos e condições de vida. Rio de Janeiro: IBGE; 2011.

GUTKOSKI, L. C.; BONAMIGO, J. M. A.; TEIXEIRA D. M. F.; PEDÓ, I. Desenvolvimento de barras de cereais à base de aveia com alto teor de fibra alimentar. Ciência Tecnologia dos Alimentos, Campinas, 27(2): 355-363, abr./jun., 2007.

INSTITUTE OF MEDICINE (IOM). Dietary reference intakes for vitamin A, vitamin K, arsenic, boron, chromium, copper, iodine, iron, manganese, molybdenum, nickel, silicon, vanadium and zinc (2001). Disponível em <http://www.nap.edu>. Acesso em 1 de outubro de 2018.

INSTITUTE OF MEDICINE (IOM). Dietary reference intakes for energy, carbohydrate, fiber, fat, fatty acids, cholesterol, protein and aminoacids (2002/2005). Disponível em <http://www.nap.edu>. Acesso em 1 de outubro de 2018.

INSTITUTE OF MEDICINE (IOM). Dietary reference intakes calcium and vitamin D (2011). Disponível em <http://www.nap.edu>. Acesso em 1 de outubro de 2018.

JORGE, K.; SPINELLI, M. G. N.; CYMROT, R.; MATIAS, A. C. G. Avaliação do consumo de arroz e feijão em uma unidade de ensino no município de São Paulo. Revista Univap, São José dos Campos-SP-Brasil, v. 20, n. 36, dez., 2014.

LANDIM, L. A. S. R.; et al. Composição química do biscoito à base de ferinha de feijão - caupi biofortificado. III CONAC - Congresso Nacional de Feijão - Caupi, Recife - PE, 22 a 24 de abril de 2013.

MARCHESE, N. R.; NOVELLO, Z. Desenvolvimento e caracterização de barra de cereal salgada. Revista Brasileira Tecnologia Agroindustrial, Ponta Grossa, v. 11, n. 1, p. 2282-2296, jan./jun., 2017. 
MELO, D. L. R.; NAVARRO, A. C.; NAVARRO, F. Elaboração de barra de cereais salgada para praticantes de atividade física. Revista Brasileira de Nutrição Esportiva, São Paulo. v. 4. n. 19. p. 50-58. Janeiro/Fevereiro, 2010.

MORAIS, P. P. P.; VALENTINI, G.; GUIDOLIN, A. F.; BALDISSERA, J. N. C.; COIMBRA, J. L. M. Influência do período e das condições de armazenamento de feijão no tempo de cocção. Revista Ciência Agronômica, v. 41, n. 4, p. 593-598, out./dez., 2010.

OLIVEIRA, E. C. T.; Produção de barra de cereal a partir da fruta do cerrado araticum (Annona crassiflora). 2015. 58 p. Monografia (Curso de Engenharia de alimentos) - Universidade Federal de Uberlândia, Patos de Minas, 2015.

PELOSO, D. et al. BRS Cometa: cultivar de feijoeiro comum do tipo comercial carioca de porte ereto. Embrapa Arroz e Feijão. Comunicado Técnico (INFOTECA-E), 2006.

PEREIRA, H. S.; et al. Estratégias de melhoramento de feijoeiro comum para altos teores de ferro e zinco. V Reunião de Biofortificação no Brasil, São Paulo - SP, 13 a 15 de outubro de 2015.

PEUCKET, Y. P.; VIERA, V. B.; HECKTHEUER, L. H.R.; MARQUES, C. T; ROSA, C. S. Caracterização e aceitabilidade de barras de cereais adicionadas de proteína texturizada de soja e camu-camu (Myrciaria dúbia). Alimentos e Nutrição, Araraquara, v. 21, n. 1, p. 147-152, jan./mar., 2010.

QUEIROZ, V. A. V.; CARNEIRO, H. L.; VASCONCELLOS, J. H.; RODRIGUES, J. A. S.; Análise sensorial de um protótipo de barras de cereais elaborada com pipoca de sorgo. Sete Lagoas, MG: EMBRAPA, 2008, 65 p. (EMBRAPA, Comunicado Técnico, 164).

REBELLO, T.G.; MAGALHÃES, C.S.; SILVA, D.A. Avaliação de formulações e composição nutricional de barra de cereais e o papel na saúde do consumidor [p.132-141]. Pesquisa em Saúde: imersão no conhecimento. Nelson Coimbra Ribeiro Neto [organizador]. 1a ed. São Paulo: Opção Livros. 2019. 256 p.

RODRIGUES, A. G. M.; PROENÇA, R. P. C.; CALVO, M. C. M.; FIATES, G. M. R. Perfil da escolha alimentar de arroz e feijão na alimentação fora de casa em restaurante de bufê por peso. Ciência \& Saúde Coletiva, 18(2):335-346, 2013.

SANTOS, J. F. Avaliação das propriedades nutricionais de barras de cereais elaboradas com farinha de banana verde. 2010. 70 p. Dissertação (Programa de Pós-Graduação em Ciência dos alimentos) Faculdade de Ciências Farmacêuticas da Universidade de São Paulo, São Paulo, 2010.

SILVA, F. D.; PANTE, C. F.; PRUDÊNCIO, S. H.; RIBEIRO, A. B. Elaboração de uma barra de cereal de quinoa e suas propriedades sensoriais e nutricionais. Alimentos e Nutrição, Araraquara, v. 22, n. 1, p. 63-69, jan./mar., 2011.

SOUSA, I. B. F.; Elaboração e avaliação sensorial de barra de cereal de arroz e feijão. 2011. 36 p. Monografia (Curso de Nutrição do Centro de Ciências Agrárias) - Universidade Federal do Espírito Santo, Alegre, 2011.

TACO. Tabela brasileira de composição de alimentos / NEPA - UNICAMP. - 4. ed. rev. e ampl. Campinas, SP: NEPA - UNICAMP, 2011. 
USDA. (United States Department of Agriculture) National Nutrient Database for Standard Reference. Disponível em <http://ndb.nal.usda.gov/ndb/foods/list.> Acesso em 25 de outubro de 2018. 